\title{
Bone Mineral Density and Body Composition of Adult Premenopausal Women with Three Levels of Physical Activity
}

\author{
Fernando D. Saraví ${ }^{1,2}$ and Fabiana Sayegh ${ }^{3,4}$ \\ ${ }^{1}$ Bone Densitometry Unit, Nuclear Medicine School, 5500 Mendoza, Argentina \\ ${ }^{2}$ Institute of Physiology, Faculty of Medical Sciences, Nacional University of Cuyo, 5500 Mendoza, Argentina \\ ${ }^{3}$ Area of Gynecology and Obstetrics, Faculty of Medical Sciences, Nacional University of Cuyo, 5500 Mendoza, Argentina \\ ${ }^{4}$ University Hospital, Nacional University of Cuyo, 5500 Mendoza, Argentina
}

Correspondence should be addressed to Fernando D. Saraví; fernando.saravi@hotmail.es

Received 30 November 2012; Revised 26 January 2013; Accepted 28 January 2013

Academic Editor: Jun Iwamoto

Copyright (C) 2013 F. D. Saraví and F. Sayegh. This is an open access article distributed under the Creative Commons Attribution License, which permits unrestricted use, distribution, and reproduction in any medium, provided the original work is properly cited.

\begin{abstract}
Weight-bearing and resistance physical activities are recommended for osteoporosis prevention, but it is unclear whether an intensity level above current recommendations has a positive effect on adult premenopausal women. Body composition and bone mineral density (BMD) by DXA were compared in three groups of women as follows: Sedentary, Maintenance exercise, and federated Sport Team ( $n=16$ for each group). Physical activity was estimated from the International Physical Activity Questionnaire (IPAQ). The groups did not differ in age, height, weight, or body mass index. Bone mineral content and non-fat soft tissue mass were higher and fat mass was lower in the Sport Team group than in the other groups. The same was true for BMD of total skeleton, lumbar spine, femoral neck, and total hip. A test for linear trend of body composition and BMD showed significant results when including all three groups. Simple and multiple regression analyses showed significant associations between physical activity level (or alternatively, years of participation in programmed physical activity) and bone mass measures at all sites except for the middle third of radius. It is concluded that a level of physical activity higher than that usually recommended benefits bone health in adult premenopausal women.
\end{abstract}

\section{Introduction}

Osteoporosis is a major public health problem worldwide [1]. Although there are effective treatments, primary prevention, mostly based on lifestyle changes, remains an essential goal to prevent both osteoporosis and its most serious consequence, namely, fragility fractures. Lifestyle changes include keeping a low alcohol intake, abstaining from smoking, maintaining adequate calcium, vitamin $\mathrm{D}$, and protein intake, and, last but not least, increasing physical activity [2].

Regularly performing weight-bearing and resistance exercises is a major lifestyle measure for osteoporosis prevention [3]. Physical activity may increase peak bone mass in children and adolescents [4]. In postmenopausal women, regular physical activity is useful for improving muscle strength and preventing falls, which is important because most fragility fractures are related to falls [2]. The role of exercise in young adult women has been less explored [5], but current evidence suggests that it has a role in maintaining or even augmenting bone mass $[6,7]$.

Although the importance of physical activity is clearly emphasized by most guidelines, some of these fail to address what its desirable frequency and duration are $[8,9]$. A brochure from the National Institutes of Health states the following: "According to the Surgeon General, the optimal goal is at least 30 minutes of physical activity on most days, preferably daily" [10]. The International Osteoporosis Foundation gives several examples of exercise schedules, one of which is " 45 to 60 minutes of weight-bearing aerobic exercise three days per week (i.e., brisk walking)" [2]. However, it is not yet clear whether higher levels of physical activity may be associated with additional benefits for bone health, particularly in young adult women. On the other hand, a syndrome characterized by disordered eating, amenorrhea, 
and osteoporosis, known as the "female athlete triad," has been described in physically active young women [11, 12].

To address this area of uncertainty, the present study compared bone mineral content (BMC), bone mineral density (BMD), and body composition in adult premenopausal women with three levels of physical activity.

\section{Materials and Methods}

2.1. Participants. This cross-sectional, observational study included 48 women divided in three groups, namely, sedentary women (Sedentary, $n=16$ ), women who regularly practiced exercise for maintenance or leisure (Maintenance, $n=16$ ), and women who belonged to a sport team (Sport Team, $n=16$ ). The participants of the latter group were recruited from nonprofessional, federated volleyball teams. The participants of the other two groups were recruited from women attending a gynecological office, direct contact at the Nuclear Medicine School, and word of mouth.

All participating women were healthy nonsmokers, had menstrual cycles within the normal range, and had completed high school (some were university students or graduates). None was taking oral contraceptives or other drugs known to affect BMD. None reported drinking more than $50 \mathrm{~g}$ of alcohol per week.

The study was planned and conducted in compliance with the current (2008) version of the Declaration of Helsinki [13]. The purpose of the study was explained both orally and through a written document to each woman, who then signed an informed consent if she agreed to participate. The study protocol was reviewed and approved by the Committee of Teaching and Research of the Nuclear Medicine School.

2.2. Assessment of Body Composition and Bone Mass. Body composition and bone mass were measured by dual-energy X-ray absorptiometry (DXA) with a Lunar Prodigy equipment (GE Lunar Health Systems, Madison, WI) in the Bone Densitometry Unit of the Nuclear Medicine School. Total body, lumbar spine (L1-L4), left hip, and forearm (middle third of radius at the nondominant side $=33 \%$ radius) scans were all performed by the same highly trained technician and analyzed by one of the authors (F. D. Saraví).

Long-term stability of the scanner was evaluated through daily measurement of a spine phantom, as recommended by the manufacturer (CV $<0.5 \%$ for BMD). Short-term precision was assessed by DXA scans repeated after repositioning the subject (two measures at each site in 30 patients) as recommended by the International Society for Clinical Densitometry [14]. For the technician who performed the scans for this study, short-term precision was $0.8 \%$ for total body, $1.0 \%$ for lumbar spine, $1.4 \%$ for femoral neck, and $1.1 \%$ for total hip.

Body composition results are expressed as total BMC, total body fat, total non-fat soft tissue mass (NFSTM), fat as a percentage of body weight, total body fat mass index, and total NFSTM index. The latter were calculated, respectively, as the quotient of total body fat $(\mathrm{kg})$ and NFSTM $(\mathrm{kg})$, each divided by height $(\mathrm{m})$ squared $[15,16]$.
2.3. Anthropometric Measures and Assessment of Calcium Intake and Menstrual Cycle. Participant height and weight was measured at the time of the DXA scans with a stadiometer and a clinical scale with a precision of $1 \mathrm{~mm}$ and $100 \mathrm{~g}$, respectively. The body mass index (BMI) was calculated as weight $(\mathrm{kg})$ divided by height $(\mathrm{m})$ squared. Calcium intake was evaluated through a validated survey [17]. Participants were asked about frequency, duration, and regularity of their menses.

2.4. Assessment of Physical Activity. All participants answered about their physical activity in the previous seven days with the self-administered, long version of the International Physical Activity Questionnaire (IPAQ) [18] available in Spanish [19]. The results were processed and analyzed according to the guidelines of the IPAQ website [20]. Results are reported as metabolic equivalent minutes per week (MET-min/week). A MET of 4 was assigned to maintenance and leisure physical activities, and a MET of 6 was assigned to volleyball playing [21].

2.5. Statistical Analysis. Data were analyzed with the commercial statistical software Prism 5.04 for Windows and InStat3 (GraphPad, San Diego, CA). The D'Agostino and Pearson omnibus normality test was routinely used to assess whether data departed significantly from a Gaussian distribution. If this was the case, data are presented as median (25-75 interquartile range). Otherwise, data are expressed as mean \pm standard deviation. Differences between groups for normally distributed data were assessed by one-way ANOVA followed by Tukey's test and a test for linear trend. Data departing significantly from a normal distribution were analyzed by Kruskall-Wallis followed by Dunn's multiple comparison test. Simple linear regression was used to assess the relationship between each of the variables physical activity, duration of practice, age, body weight, BMI, total fat mass, total NFSTM, total body fat mass index, and total NFSTM index on one hand and total BMC and BMD at total body, lumbar spine, femoral neck, total hip, and forearm (33\% radius) on the other. The variables showing significant correlation with simple linear regression were then included in a multiple regression analysis with physical activity, duration of practice, body weight, BMI, NFSTM, fat mass, NFSTM index, and fat mass index as independent variables, to find out which of them were best correlated with BMC and BMD. A value of $P<0.05$ was deemed significant.

\section{Results and Discussion}

There was no significant difference in age, height, weight, BMI, or calcium intake among the three groups, while their physical activity level was significantly different (Table 1). The maintenance group had programmed physical activity with a median of $3 \mathrm{~h} /$ week (interquartile range 2 to $3 \mathrm{~h} /$ week, range 2 to $4 \mathrm{~h} /$ week) during $3.4 \pm 1.7$ years, while the Sport Team group had a median of $6 \mathrm{~h} /$ week (interquartile range 5 to $6 \mathrm{~h} /$ week, range 4 to $6 \mathrm{~h} /$ week) during $6.5 \pm 1.8$ years. The small range of time devoted to physical activity by the Sports 
TABLE 1: Characteristics of participants ${ }^{\mathrm{a}}$.

\begin{tabular}{|c|c|c|c|c|}
\hline & Sedentary $(n=16)$ & Maintenance $(n=16)$ & Sport Team $(n=16)$ & $P^{\mathrm{b}}$ \\
\hline Age (years) & $33.5 \pm 5.8$ & $34.0 \pm 5.0$ & $32.4 \pm 8.5$ & 0.7770 \\
\hline Height $(\mathrm{cm})$ & $161.0 \pm 5.0$ & $161.0 \pm 3.0$ & $164 \pm 6.0$ & 0.1681 \\
\hline Weight (kg) & $61.6 \pm 6.5$ & $57.5 \pm 5.3$ & $60.5 \pm 8.7$ & 0.2434 \\
\hline Body mass index $\left(\mathrm{kg} / \mathrm{m}^{2}\right)$ & $23.5 \pm 1.8$ & $22.2 \pm 1.8$ & $22.5 \pm 2.5$ & 0.1738 \\
\hline Calcium intake $(\mathrm{mg} / \mathrm{day})^{\mathrm{c}}$ & $500(400-800)$ & $400(400-800)$ & $800(400-1100)$ & 0.1026 \\
\hline Physical activity (MET-min/week) & $485 \pm 152$ & $667 \pm 127^{\mathrm{d}}$ & $1115 \pm 175^{\mathrm{e}}$ & $<0.0001$ \\
\hline
\end{tabular}

"Values are mean \pm standard deviation except for calcium intake, which is median (interquartile range).

${ }^{\mathrm{b}}$ Assessed by ANOVA, except for calcium intake, in which Kruskall-Wallis nonparametric test was used.

${ }^{c}$ The ranges of calcium intake were (in mg/day) 200 to 1000 for the Sedentary group, 100 to 1200 for the Maintenance group, and 400 to 1200 for the Sports group.

${ }^{\mathrm{d}}$ Different from Sedentary $(P<0.01)$

${ }^{\mathrm{e}}$ Different from Sedentary and Maintenance (both $P<0.001$ ).

TABLE 2: Body composition results.

\begin{tabular}{lcccc}
\hline & Sedentary $(n=16)$ & Maintenance $(n=16)$ & Sport Team $(n=16)$ & Linear trend $P^{\mathrm{a}}$ \\
\hline Bone mineral content $(\mathrm{g})$ & $2295 \pm 260$ & $2431 \pm 321$ & $2730 \pm 375^{\mathrm{b}}$ & 0.0004 \\
Fat mass $(\mathrm{kg})$ & $21.23 \pm 3.59$ & $17.71 \pm 5.18$ & $15.68 \pm 5.42^{\mathrm{c}}$ & 0.0021 \\
Non-fat soft tissue mass $(\mathrm{kg})$ & $38.07 \pm 4.37$ & $37.74 \pm 3.75$ & $42.55 \pm 3.98^{\mathrm{d}}$ & 0.0030 \\
Body fat $(\%)$ & $34.3 \pm 3.9$ & $30.3 \pm 7.3$ & $25.2 \pm 5.6^{\mathrm{b}}$ & $<0.0001$ \\
Fat mass index $\left(\mathrm{kg} / \mathrm{m}^{2}\right)$ & $8.2 \pm 1.3$ & $6.8 \pm 2.0$ & $5.8 \pm 1.8$ & 0.0004 \\
Non-fat soft tissue mass index $\left(\mathrm{kg} / \mathrm{m}^{2}\right)$ & $14.6 \pm 1.2$ & $14.6 \pm 1.2$ & $15.9 \pm 1.0$ & 0.0045 \\
\hline
\end{tabular}

${ }^{a}$ For linear trend post hoc test after a significant result with ANOVA.

${ }^{\mathrm{b}}$ Significantly different from Sedentary $(P<0.01)$ and Maintenance $(P<0.05)$.

${ }^{\mathrm{c}}$ Significantly different from Sedentary and Maintenance (both $P<0.01$ ).

${ }^{\mathrm{d}}$ Significantly different from Sedentary $(P<0.01)$.

${ }^{\mathrm{e}}$ Significantly different from Sedentary $(P<0.05)$ and Maintenance $(P<0.01)$.

group is due to the fact that they trained together. The small range of time devoted to physical activity by the Maintenance group is due to the study design, since we wished to assess a moderately active group.

The results of body composition analysis are summarized in Table 2. Although the groups did not differ in BMI, differences were found for all variables, with significant linear trends when all three groups were compared. However, the mean values of BMC, fat mass, NFSTM, $\%$ body fat, fat mass index, and NFSTM index were not significantly different between the Sedentary and the Maintenance groups. BMD results, shown in Table 3, showed significant linear trends for the three groups, and the mean values of the Sport Team were significantly higher (except for $33 \%$ radius) than those of the Sedentary and Maintenance groups, which in turn did not differ between them.

For simple linear regression, physical activity and duration of practice were selected as independent variables because they were germane to the study. The influence of age was analyzed because the sample included women with ages ranging from 21 to 46 years. While some studies reported no significant influence of age on BMD within this age range $[22,23]$, other studies have shown an inverse correlation between age and BMD at the lumbar spine, femoral neck, and forearm [24], or a direct correlation between age and lumbar spine BMD $[25,26]$ and a negative correlation at the femoral neck [26]. Additionally, the age at which peak BMD is reached may differ between sites and different populations [27-30]. Body weight [31-33] and BMI [31,34,35] are strong predictors of BMD. NFSTM is also positively correlated with BMD in young women $[32,36-40]$. The influence of fat mass on BMD in this age group is more controversial, since different groups have reported no association [32], a positive association [37-39], or a negative association [41] (see [42] for a recent review). Fat mass index and NFSTM index were analyzed as measures of fat mass and NFSTM, respectively, normalized for height [15].

Simple linear regression results are shown in Table 4. The age of the participants had no correlation with BMC or $B M D$, except for a slight negative influence on femoral neck BMD. Fat mass had no correlation with BMC or BMD at any site except for a weak positive relationship with $33 \%$ radius BMD; neither the former nor the latter were significant for fat mass index. On the other hand, NFSTM and NFSTM index were significantly correlated with BMC and with BMD at all sites. Body weight was positively and significantly related with $\mathrm{BMC}$ and $\mathrm{BMD}$ at the lumbar spine and $33 \%$ radius, but not femoral neck nor total hip BMD. Physical activity level 
TABLE 3: Bone mineral density results.

\begin{tabular}{lcccc}
\hline Site & Sedentary $(n=16)$ & Maintenance $(n=16)$ & Sport Team $(n=16)$ & Linear trend $P^{\mathrm{a}}$ \\
\hline Total body & $1.117 \pm 0.069$ & $1.132 \pm 0.071$ & $1.220 \pm 0.087^{\mathrm{b}}$ & 0.0004 \\
Lumbar spine & $1.153 \pm 0.107$ & $1.189 \pm 0.125$ & $1.358 \pm 0.177^{\mathrm{b}}$ & 0.0001 \\
Femoral neck & $0.942 \pm 0.103$ & $0.950 \pm 0.102$ & $1.153 \pm 0.186^{\mathrm{b}}$ & $<0.0001$ \\
Total hip & $0.932 \pm 0.085$ & $0.957 \pm 0.110$ & $1.159 \pm 0.180^{\mathrm{b}}$ & $<0.0001$ \\
$33 \%$ radius & $0.686 \pm 0.053$ & $0.681 \pm 0.042$ & $0.705 \pm 0.072$ & Not calculated $^{\mathrm{c}}$ \\
\hline
\end{tabular}

${ }^{\mathrm{a}}$ For linear trend post-hoc test after a significant result with ANOVA.

${ }^{\mathrm{b}}$ Significantly different from Sedentary and Maintenance (both $P<0.01$ ).

${ }^{\mathrm{c}}$ For the $33 \%$ radius site, $P$ for ANOVA was 0.4606 .

TABLE 4: Simple linear regression results for all three groups $(n=48)$.

\begin{tabular}{|c|c|c|c|c|c|c|}
\hline Independent variable & $\mathrm{BMC}(\mathrm{g})$ & $\begin{array}{c}\text { BMD total } \\
\text { skeleton }\left(\mathrm{g} / \mathrm{cm}^{2}\right)\end{array}$ & $\begin{array}{l}\text { BMD lumbar } \\
\text { spine }\left(\mathrm{g} / \mathrm{cm}^{2}\right)\end{array}$ & $\begin{array}{l}\text { BMD femoral } \\
\text { neck }\left(\mathrm{g} / \mathrm{cm}^{2}\right)\end{array}$ & $\begin{array}{l}\text { BMD total } \\
\text { hip }\left(\mathrm{g} / \mathrm{cm}^{2}\right) \\
\end{array}$ & $\begin{array}{c}\text { BMD } 33 \% \text { radius } \\
\left(\mathrm{g} / \mathrm{cm}^{2}\right)\end{array}$ \\
\hline \multirow{2}{*}{ Age (years) } & $R=0.0308$ & $R=0.0173$ & $R=0.0958$ & $R=0.3170$ & $R=0.2057$ & $R=0.0936$ \\
\hline & $P=0.8352$ & $P=0.9074$ & $P=0.5173$ & $P=0.0281$ & $P=0.1601$ & $P=0.5268$ \\
\hline \multirow{2}{*}{$\begin{array}{l}\text { Duration of practice } \\
\text { (years) }\end{array}$} & $R=0.4523$ & $R=0.4576$ & $R=0.4516$ & $R=0.5202$ & $R=0.5394$ & $R=0.1555$ \\
\hline & $P=0.0012$ & $P=0.0011$ & $P=0.0013$ & $P=0.0002$ & $P<0.0001$ & $P=0.2913$ \\
\hline \multirow{2}{*}{$\begin{array}{l}\text { Physical activity } \\
\text { (MET-min/week) }\end{array}$} & $R=0.5065$ & $R=0.4704$ & $R=0.4919$ & $R=0.5303$ & $R=0.5563$ & $R=0.1026$ \\
\hline & $P=0.0002$ & $P=0.0007$ & $P=0.0004$ & $P=0.0001$ & $P<0.0001$ & $P=0.4876$ \\
\hline \multirow{2}{*}{ Weight (kg) } & $R=0.6055$ & $R=0.3407$ & $R=0.3315$ & $R=0.2012$ & $R=0.1573$ & $R=0.4433$ \\
\hline & $P<0.0001$ & $P=0.0178$ & $P=0.0214$ & $P=0.1702$ & $P=0.2858$ & $P=0.0016$ \\
\hline \multirow{2}{*}{$\mathrm{BMI}\left(\mathrm{kg} / \mathrm{m}^{2}\right)$} & $R=0.3500$ & $R=0.1876$ & $R=0.2282$ & $R=0.1391$ & $R=0.1031$ & $R=0.3607$ \\
\hline & $P=0.0147$ & $P=0.2017$ & $P=0.1188$ & $P=0.3456$ & $P=0.4859$ & $P=0.0118$ \\
\hline \multirow{2}{*}{ Body fat mass $(\mathrm{kg})$} & $R=0.2730$ & $R=0.0151$ & $R=0.0965$ & $R=0.0896$ & $R=0.1127$ & $R=0.3158$ \\
\hline & $P=0.0606$ & $P=0.9188$ & $P=0.5143$ & $P=0.5449$ & $P=0.4457$ & $P=0.0288$ \\
\hline \multirow{2}{*}{ NFSTM (kg) } & $R=0.5667$ & $R=0.4696$ & $R=0.3548$ & $R=0.3762$ & $R=0.3348$ & $R=0.2864$ \\
\hline & $P<0.0001$ & $P=0.0008$ & $P=0.0133$ & $P=0.0084$ & $P=0.0200$ & $P=0.0484$ \\
\hline \multirow{2}{*}{$\begin{array}{l}\text { Body fat mass index } \\
\left(\mathrm{kg} / \mathrm{m}^{2}\right)\end{array}$} & $R=0.1447$ & $R=0.0689$ & $R=0.0250$ & $R=0.1375$ & $R=0.1555$ & $R=0.2475$ \\
\hline & $P=0.3263$ & $P=0.2194$ & $P=0.8861$ & $P=0.3514$ & $P=0.2912$ & $P=0.0899$ \\
\hline \multirow{2}{*}{ NFSTM Index $\left(\mathrm{kg} / \mathrm{m}^{2}\right)$} & $R=0.3189$ & $R=0.3956$ & $R=0.2593$ & $R=0.3528$ & $R=0.3291$ & $R=0.1803$ \\
\hline & $P=0.0271$ & $P=0.0054$ & $P=0.0751$ & $P=0.0139$ & $P=0.0224$ & $P=0.2201$ \\
\hline
\end{tabular}

BMC: total bone mineral content; BMD: bone mineral density; BMI: body mass index; NFSTM: non-fat soft tissue mass.

$R$ : Pearson's coefficient of correlation. Values of $P$ indicate the probability of the slope between the independent and the dependent variable being nonsignificantly different from zero.

and time on programmed physical activity (set at 0 for the sedentary group) were significantly correlated with all bone parameters except for $33 \%$ radius BMD.

The main results of multiple regression analysis are featured in Table 5. The coefficient of determination $\left(R^{2}\right)$ depicts the fraction of total variance of the dependent variable which is explained by the model.

It can be seen that either the level physical activity or duration of activity (the number of years during which that level had been sustained) is included in all models. It was not possible to include physical activity and duration of activity simultaneously in the models because of colinearity $(R=$ 0.823 ). The highest values of $R^{2}$ were found for the models incorporating physical activity or duration of practice plus body weight and for those incorporating physical activity or duration of practice plus NFSTM plus fat mass. Similar results were obtained when body weight was replaced by BMI, although with generally lower $R^{2}$ values. This is in agreement with a study suggesting that BMI is inferior to body weight as a predictor of BMD [43]. In the models incorporating NFSTM and fat mass, the influence of fat mass was larger for total body BMC, lumbar spine, and $33 \%$ radius, while NFSTM was more important than fat mass for total body BMD.

Limitations of this study include those inherent to crosssectional comparison, a relatively small sample, and the fact that physical activity was measured indirectly, through the IPAQ instrument.

The Sport Team group differed from the Sedentary and Maintenance groups in all measures of body composition. They had higher BMC and NFSTM and lower fat mass than both the Sedentary and the Maintenance groups. The same was found for BMD of total skeleton, lumbar spine, femoral neck, and total hip. 
TABLE 5: Selected multiple regression results for all three groups $(n=48)$.

\begin{tabular}{lcccccc}
\hline Independent variables & BMC $(\mathrm{g})$ & $\begin{array}{c}\text { BMD total } \\
\text { skeleton }\left(\mathrm{g} / \mathrm{cm}^{2}\right)\end{array}$ & $\begin{array}{c}\text { BMD lumbar } \\
\text { spine }\left(\mathrm{g} / \mathrm{cm}^{2}\right)\end{array}$ & $\begin{array}{c}\text { BMD femoral } \\
\text { neck }\left(\mathrm{g} / \mathrm{cm}^{2}\right)\end{array}$ & $\begin{array}{c}\text { BMD total } \\
\text { hip }\left(\mathrm{g} / \mathrm{cm}^{2}\right)\end{array}$ & $\begin{array}{c}\text { BMD 33\% radius } \\
\left(\mathrm{g} / \mathrm{cm}^{2}\right)\end{array}$ \\
\hline Physical activity & $R^{2}=0.568$ & $R^{2}=0.309$ & $R^{2}=0.323$ & $R^{2}=0.334$ & $R^{2}=0.320$ & $R^{2}=0.200$ \\
and body weight & $P<0.0001$ & $P=0.0002$ & $P=0.0002$ & $P=0.0001$ & $P=0.0002$ & $P=0.0066$ \\
Duration of practice and & $R^{2}=0.629$ & $R^{2}=0.358$ & $R^{2}=0.345$ & $R^{2}=0.358$ & $R^{2}=0.335$ & $R^{2}=0.236$ \\
body weight & $P=0.0004$ & $P<0.0001$ & $P<0.0001$ & $P<0.0001$ & $P=0.0001$ & $P=0.0024$ \\
Physical activity & $R^{2}=0.410$ & $R^{2}=0.272$ & $R^{2}=0.314$ & $R^{2}=0.314$ & $R^{2}=0.332$ & $R^{2}=0.147$ \\
and BMI & $P<0.0001$ & $P=0.0008$ & $P=0.0002$ & $P=0.0002$ & $P=0.0001$ & $P=0.0275$ \\
Duration of practice and & $R^{2}=0.426$ & $R^{2}=0.302$ & $R^{2}=0.323$ & $R^{2}=0.344$ & $R^{2}=0.347$ & $R^{2}=0.192$ \\
BMI & $P<0.0001$ & $P=0.0002$ & $P=0.0002$ & $P<0.0001$ & $P<0.0001$ & $P=0.0083$ \\
Physical activity, NFSTM, & $R^{2}=0.555$ & $R^{2}=0.315$ & $R^{2}=0.317$ & $R^{2}=0.303$ & $R^{2}=0.317$ & $R^{2}=0.195$ \\
and fat mass & $P<0.0001$ & $P=0.0008$ & $P=0.0007$ & $P=0.0011$ & $P=0.0007$ & $P=0.0215$ \\
Duration of practice, & $R^{2}=0.622$ & $R^{2}=0.346$ & $R^{2}=0.346$ & $R^{2}=0.327$ & $R^{2}=0.329$ & $R^{2}=0.249$ \\
NFSTM, and fat mass & $P<0.0001$ & $P=0.0002$ & $P=0.0003$ & $P=0.0005$ & $P=0.0005$ & $P=0.0052$ \\
\hline
\end{tabular}

BMC: total bone mineral content; BMD: bone mineral density; BMI: body mass index; NFSTM: non-fat soft tissue mass. The units of the independent variables are the same indicated in Table 4.

$R^{2}$ : coefficient of determination. Values of $P$ correspond to the probability of $R^{2}$ of attaining the displayed value or a higher one by chance.

However, no significant difference in means other than in physical activity level was found between the Sedentary and the Maintenance groups. This may be due in part to the small sample size, since tests for linear trend including all three groups were significant for all measures except for $33 \%$ radius BMD. Additionally, both in simple regression and multiple regression, it was found that both physical activity level and duration of practice had a strong correlation with BMC and total skeleton, lumbar spine, femoral neck, and total hip BMD, but not with 33\% radius BMD.

While it has been suggested that high-intensity resistance training has site-specific effects on BMD; namely, it increases lumbar spine, but not femoral neck BMD [44], a more recent meta-analysis indicates that this may not be the case [7]. In the present series, a robust difference for both femoral neck and total hip BMDs was found between the Sport Team group and both the Sedentary and Maintenance groups. This observation agrees with findings of a recent population-based study of more than one thousand 25-yearold women reporting recreational exercise, in whom a larger BMD difference was found in the femoral neck than in the lumbar spine [45]. Another study found that recreational football increased volumetric BMD in the tibia after a 14-week training course [46].

The importance of combining both regularity and impact for highest positive effects on bone mass has been emphasized [45]. In the present study, both the years during which programmed physical activity was performed and its level of intensity were significantly associated with measures of bone mass, except at 33\% radius. Thus, while for older patients the best practical advice may be to walk 30 to $60 \mathrm{~min}$ per day on most days [47], younger women can benefit from more demanding schedules combining high impact and regularity-not just in bone health $[3,48]$. The characteristics of training for the federated Sport Team participants were such that it should not raise particular concern for the "female athlete triad" [11, 12], although it is advisable to screen all physically active women for this condition [49].

\section{Conclusion}

A higher than usually recommended level of physical activity for adult premenopausal women is associated with higher BMC and NFSTM, lower body fat mass, and higher BMD. Therefore, regarding bone health (and other possible health benefits), young women should be encouraged to engage in that level, provided they are willing to make it regularly.

\section{Conflict of Interests}

The authors have no conflict of interests regarding this study.

\section{Acknowledgments}

The foundation of the Nuclear Medicine School allowed the DXA scans to be performed. The collaboration of the Licentiates in physical education Sergio Furlán, Anabel Prado and Marcelo Sabatini is gratefully acknowledged. Technician María Angélica Andrada performed all DXA scans with her usual skill. Thanks go also to Technicians Patricia Ortiz and Carolina Miranda for their support.

\section{References}

[1] WHO Scientific Group on the Assessment of Osteoporosis at Primary Care Level, Summary Meeting Report. Brussels, Belgium, 5-7 May 2004, World Health Organization, Geneva, Switzerland, 2007.

[2] H. A. Bischoff-Ferrari, “Three steps to unbreakable bones. Vitamin D, calcium and exercise," 2011, International Osteoporosis Foundation, Nyon, Switzerland, http://www.iofbonehealth .org/. 
[3] J. L. Thompson, "Exercise in improving health v. performance," Proceedings of the Nutrition Society, vol. 68, no. 1, pp. 29-33, 2009.

[4] M. K. Karlsson and B. E. Rosengren, "Training and bone-from health to injury," Scandinavian Journal of Medicine and Science in Sports, vol. 22, pp. e15-e23, 2012.

[5] M. Karlsson, "Has exercise an antifracture efficacy in women?" Scandinavian Journal of Medicine and Science in Sports, vol. 14, no. 1, pp. 2-15, 2004.

[6] S. L. Manske, C. R. Lorincz, and R. F. Zernicke, "Bone health, part 2: physical activity," Sports Health, vol. 1, no. 4, pp. 341-346, 2009.

[7] M. Martyn-St James and S. Carroll, "Effects of different impact exercise modalities on bone mineral density in premenopausal women: a meta-analysis," Journal of Bone and Mineral Metabolism, vol. 28, no. 3, pp. 251-267, 2010.

[8] Consenso Iberoamericano de Osteoporosis SIBOMM, 2009, Osteoporosis: Prevención, diagnóstico y tratamiento. Sociedad Iberoamericana de Osteología y Metabolismo, Mineral, http:// www.ammom.com.mx/AMMOM/Consenso_SIBOMM2009 .pdf.

[9] National Osteoporosis Foundation, Clinician's Guide to Prevention and Treatment of Osteoporosis, National Osteoporosis Foundation, Washington, DC, USA, 2010.

[10] NIH Osteoporosis and Related Bone Diseases National Resource Center, "Exercise for your bone health," http://www .niams.nih.gov/Health_Info/Bone/Bone_Health/Exercise/exercise_bone_health.pdf.

[11] C. L. Otis, B. Drinkwater, M. Johnson, A. Loucks, and J. Wilmore, "American College of Sports Medicine position stand. The female athlete triad," Medicine and Science in Sports and Exercise, vol. 29, no. 5, pp. 1-9, 1997.

[12] K. Birch, "ABC of sports and exercise medicine: female athlete triad," British Medical Journal, vol. 330, no. 7485, pp. 244-246, 2005.

[13] World Medical Association, "Declaration of Helsinki-ethical principles for medical research involving human subjects," in Proceedings of the 59th WMA General Assembly, Seoul, Korea, October 2008.

[14] International Society for Clinical Densitometry, 2007 Official Positions and Pediatric Official Positions, http://www.iscd.org/ Visitors/pdfs/ISCD2007OfficialPositions-Combined-AdultandPediatric.pdf.

[15] Y. Schutz, U. U. G. Kyle, and C. Pichard, "Fat-free mass index and fat mass index percentiles in caucasians aged 18-98y," International Journal of Obesity, vol. 26, no. 7, pp. 953-960, 2002.

[16] F. Nourhashémi, S. Andrieu, S. Gillette-Guyonnet et al., "Is there a relationship between fat-free soft tissue mass and low cognitive function? Results from a study of 7,105 women," Journal of the American Geriatrics Society, vol. 50, no. 11, pp. 1796-1801, 2002.

[17] D. C. Welten, H. C. G. Kemper, G. B. Post, and W. A. van Staveren, "Comparison of a quantitative dairy questionnaire with a dietary history in young adults," International Journal of Epidemiology, vol. 24, no. 4, pp. 763-770, 1995.

[18] C. L. Craig, A. L. Marshall, M. Sjöström et al., "International Physical Activity Questionnaire: 12-country reliability and validity," Medicine and Science in Sports and Exercise, vol. 35, no. 8, pp. 1381-1395, 2003.

[19] International Physical Activity Questionnaire, "Versión larga formato auto administrado-últimos 7 días," 2003, IPAQ, http://www.ipaq.ki.se.
[20] International Physical Activity Questionnaire, "Guidelines for data processing and analysis of the International Physical Activity Questionnaire (IPAQ) - short and long forms," 2005, IPAQ, http://www.ipaq.ki.se.

[21] M. Jette, K. Sidney, and G. Blumchen, "Metabolic equivalents (METS) in exercise testing, exercise prescription, and evaluation of functional capacity," Clinical Cardiology, vol. 13, no. 8, pp. 555-565, 1990.

[22] R. B. Mazess and H. S. Barden, "Bone density in premenopausal women: effects of age, dietary intake, physical activity, smoking, and birth-control pills," American Journal of Clinical Nutrition, vol. 53, no. 1, pp. 132-142, 1991.

[23] O. Löfman, L. Larsson, I. Ross, G. Toss, and K. Berglund, "Bone mineral density in normal Swedish women," Bone, vol. 20, no. 2, pp. 167-174, 1997.

[24] R. J. MacInnis, C. Cassar, C. A. Nowson et al., "Determinants of bone density in 30- to 65-year-old women: a co-twin study," Journal of Bone and Mineral Research, vol. 18, no. 9, pp. 16501656, 2003.

[25] J. P. Sabatier, G. Guaydier-Souquières, A. Benmalek, and C. Marcelli, "Evolution of lumbar bone mineral content during adolescence and adulthood: a longitudinal study in 395 healthy females 10-24 years of age and 206 premenopausal women," Osteoporosis International, vol. 9, no. 6, pp. 476-482, 1999.

[26] S. Chanprasertyothin, S. Saetung, P. Payattikul, R. Rajatanavin, and B. Ongphiphadhanakul, "Relationship of body composition and circulatory adiponectin to bone mineral density in young premenopausal women," Journal of the Medical Association of Thailand, vol. 89, no. 10, pp. 1579-1583, 2006.

[27] S. Lewin, C. H. Gouveia, M. M. Marone, S. Wehba, L. F. Malvestiti, and A. C. Bianco, "Densidade mineral óssea vertebral e femoral de 724 mulheres brancas brasileiras: influência da idade e do peso corporal," Revista da Associação Médica Brasileira, vol. 43, no. 2, pp. 127-136, 1997.

[28] C. Blanchet, S. Dodin, M. Dumont et al., "Bone mineral density in French Canadian women," Osteoporosis International, vol. 8, no. 3, pp. 268-273, 1998.

[29] H. T. T. Nguyen, B. Von Schoultz, D. M. T. Pham et al., "Peak bone mineral density in Vietnamese women," Archives of Osteoporosis, vol. 4, no. 1-2, pp. 9-15, 2009.

[30] Q. Cheng, Y. X. Zhu, M. X. Zhang, L. H. Li, P. Y. Du, and M. $\mathrm{H}$. Zhu, "Age and sex effects on the association between body composition and bone mineral density in healthy Chinese men and women," Menopause, vol. 19, no. 4, pp. 448-455, 2012.

[31] D. T. Felson, Y. Zhang, M. T. Hannan, and J. J. Anderson, "Effects of weight and body mass index on bone mineral density in men and women: the Framingham study," Journal of Bone and Mineral Research, vol. 8, no. 5, pp. 567-573, 1993.

[32] H. Rico, M. Revilla, L. F. Villa, M. A. del Buergo, and D. Ruiz-Contreras, "Determinants of total-body and regional bone mineral content and density in postpubertal normal women," Metabolism, vol. 43, no. 2, pp. 263-266, 1994.

[33] N. K. Henderson, R. I. Price, J. H. Cole, D. H. Gutteridge, and C. I. Bhagat, "Bone density in young women is associated with body weight and muscle strength but not dietary intakes," Journal of Bone and Mineral Research, vol. 10, no. 3, pp. 384-393, 1993.

[34] L. Langsetmo, C. L. Hitchcock, E. J. Kingwell et al., "Physical activity, body mass index and bone mineral densityassociations in a prospective population-based cohort of women and men: the Canadian Multicentre Osteoporosis Study (CaMos)," Bone, vol. 50, no. 1, pp. 401-408, 2012. 
[35] T. Puntus, B. Schneider, J. Meran, M. Peterlik, and S. Kudlacek, "Influence of age and gender on associations of body mass index with bone mineral density, bone turnover markers and circulating calcium-regulating and bone-active sex hormones," Bone, vol. 49, no. 4, pp. 824-829, 2011.

[36] T. Douchi, T. Oki, S. Nakamura, H. Ijuin, S. Yamamoto, and Y. Nagata, "The effect of body composition on bone density in preand postmenopausal women," Maturitas, vol. 27, no. 1, pp. 5560, 1997.

[37] I. Bakker, J. W. R. Twisk, W. Van Mechelen, and H. C. G. Kemper, "Fat-free body mass is the most important body composition determinant of 10-yr longitudinal development of lumbar bone in adult men and women," Journal of Clinical Endocrinology and Metabolism, vol. 88, no. 6, pp. 2607-2613, 2003.

[38] S. Lekamwasam, T. Weerarathna, M. Rodrigo, W. K. Arachchi, and D. Munidasa, "Association between bone mineral density, lean mass, and fat mass among healthy middle-aged premenopausal women: a cross-sectional study in southern Sri Lanka," Journal of Bone and Mineral Metabolism, vol. 27, no. 1, pp. 83-88, 2009.

[39] M. C. Wang, L. K. Bachrach, M. Van Loan, M. Hudes, K. M. Flegal, and P. B. Crawford, "The relative contributions of lean tissue mass and fat mass to bone density in young women," Bone, vol. 37, no. 4, pp. 474-481, 2005.

[40] D. A. Kerr, S. Papalia, A. Morton, I. Dick, S. Dhaliwal, and R. L. Prince, "Bone mass in young women is dependent on lean body mass," Journal of Clinical Densitometry, vol. 10, no. 3, pp. 319-326, 2007.

[41] H. J. Yoo, M. S. Park, S. J. Yang et al., "The differential relationship between fat mass and bone mineral density by gender and menopausal status," Journal of Bone and Mineral Metabolism, vol. 30, no. 1, pp. 47-53, 2012.

[42] I. R. Reid, "Fat and bone," Archives of Biochemistry and Biophysics, vol. 503, no. 1, pp. 20-27, 2010.

[43] J. Robbins, A. M. Schott, R. Azari, and R. Kronmal, "Body mass index is not a good predictor of bone density: results from WHI, CHS, and EPIDOS," Journal of Clinical Densitometry, vol. 9, no. 3, pp. 329-334, 2006.

[44] M. M. S. James and S. Carroll, "Progressive high-intensity resistance training and bone mineral density changes among premenopausal women: evidence of discordant site-specific skeletal effects," Sports Medicine, vol. 36, no. 8, pp. 683-704, 2006.

[45] M. Callréus, F. McGuigan, K. Ringsberg, and K. Åkesson, "Selfreported recreational exercise combining regularity and impact is necessary to maximize bone mineral density in young adult women. A population-based study of 1, 061 women 25 years of age," Osteoporosis International, vol. 23, no. 10, pp. 2517-2526, 2012.

[46] E. W. Helge, P. Aagaard, M. D. Jakobsen et al., "Recreational football training decreases risk factors for bone fractures in untrained premenopausal women," Scandinavian Journal of Medicine and Science in Sports, vol. 20, supplement 1, pp. 31-39, 2010.

[47] P. Bergmann, J. J. Body, S. Boonen et al., "Loading and skeletal development and maintenance," Journal of Osteoporosis, vol. 2011, Article ID 786752, 15 pages, 2011.

[48] W. L. Haskell, I. M. Lee, R. R. Pate et al., "Physical activity and public health: updated recommendation for adults from the American College of Sports Medicine and the American Heart Association," Medicine and Science in Sports and Exercise, vol. 39, no. 8, pp. 1423-1434, 2007.
[49] M. K. Torstveit and J. Sundgot-Borgen, "The female athlete triad exists in both elite athletes and controls," Medicine and Science in Sports and Exercise, vol. 37, no. 9, pp. 1449-1459, 2005. 


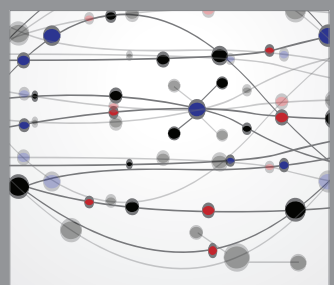

The Scientific World Journal
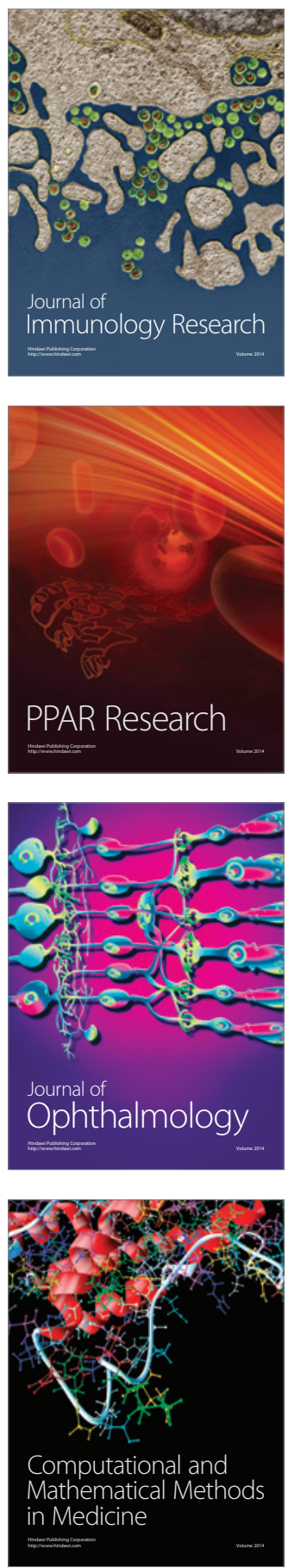

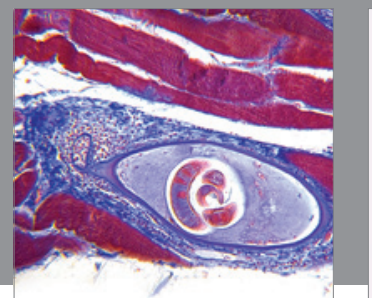

Gastroenterology

Research and Practice
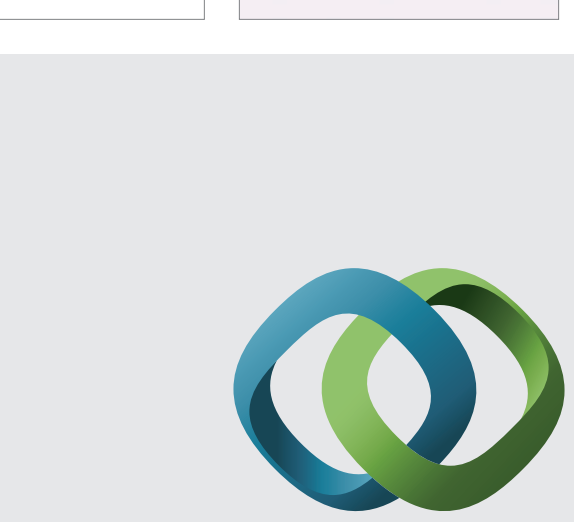

\section{Hindawi}

Submit your manuscripts at

http://www.hindawi.com
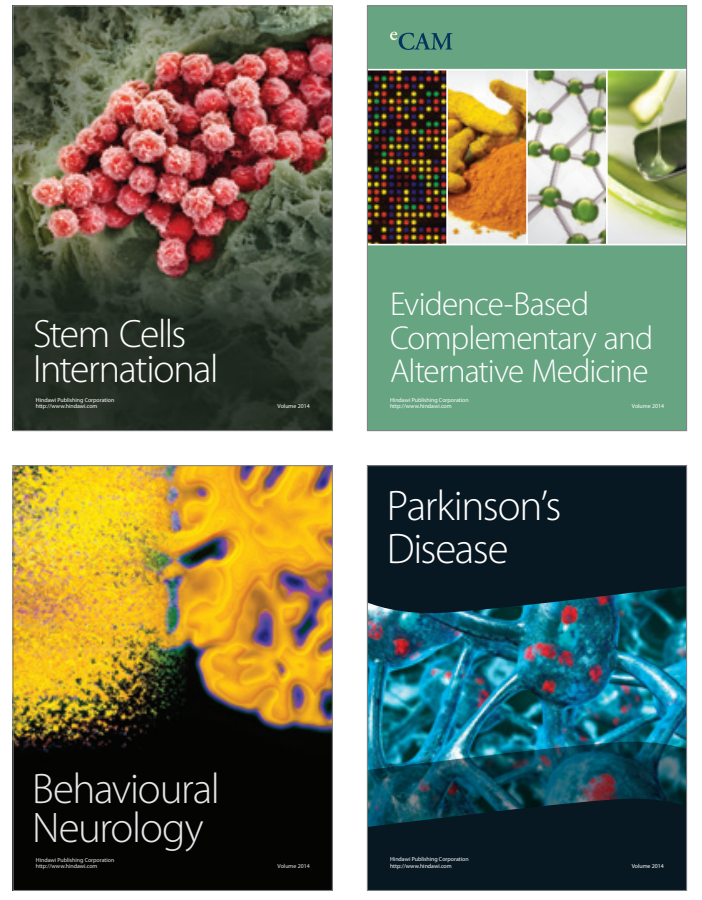
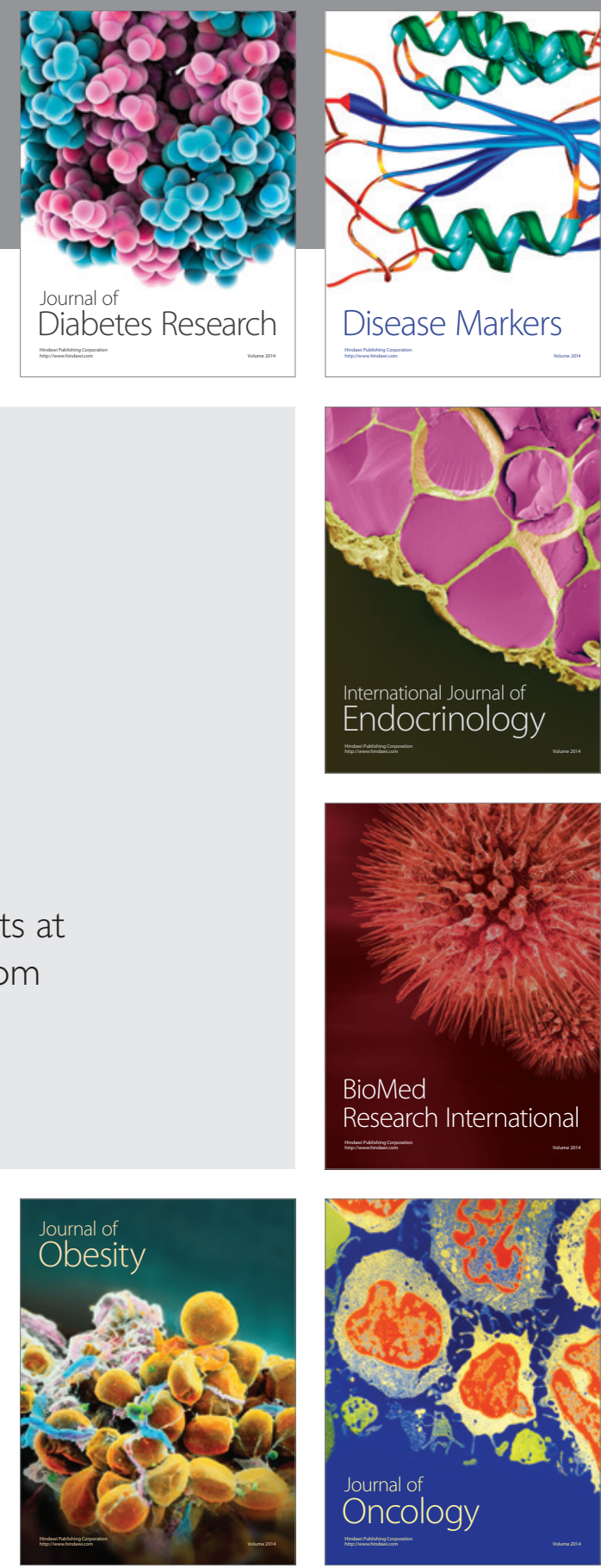

Disease Markers
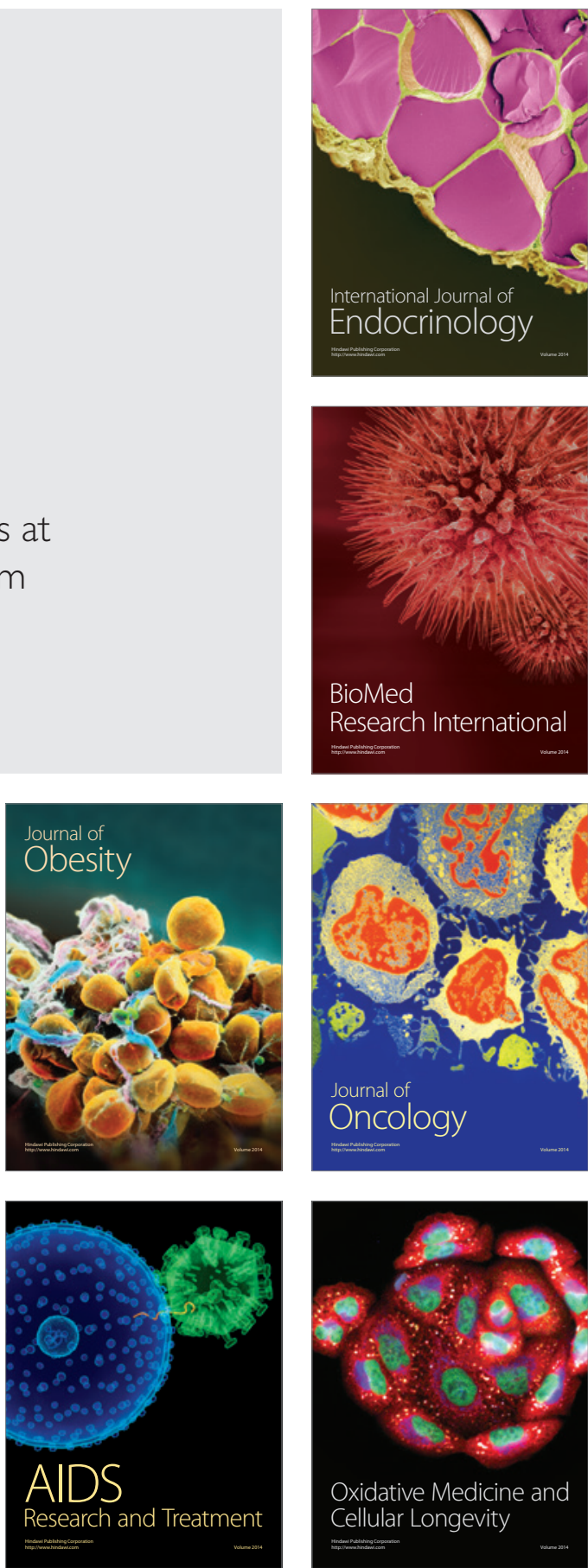